\title{
Kick-Off Editorial for 2016: Thanks to Our Reviewers
}

\author{
Stephen M. Stahl, MD, PhD
}

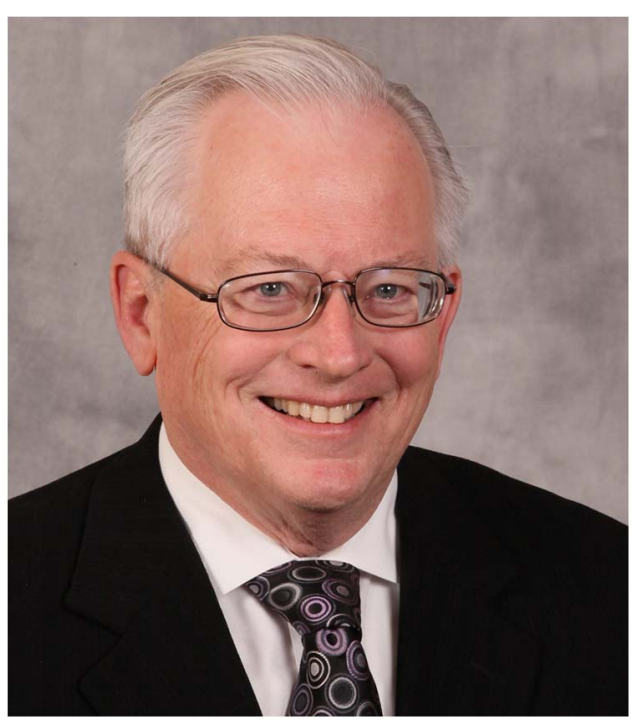

The year 2015 was a terrific year for CNS Spectrums: our first impact factor based on content generated following the transition of the journal to Cambridge University Press and my appointment as editor-in-chief nearly doubled to 2.71 and early indications are that it will go even higher in 2016. Downloads of our articles are exploding and we are getting higher and higher quality manuscripts every day. In 2015 we published several high impact thematic issues for which we owe special thanks to a number of guest editors including:

- our second special issue on violence (Guest editor Katherine Warburton)

\section{CNS Spectrums 2015 peer reviewers}

Thierry Alquier

Daniel Antonius

Shannon Bader

Michael Barsom

Mace Beckson

Nicolas Bello
- antidepressants and pregnancy (Guest editors Patrick Finley and Luann Brizendine)

- pediatric neuroimaging (Guest editors Susan Carnell, Karen Seymour and Robert Findling)

- binge eating disorder (Guest editor Valerie Voon)

- obsessive compulsive disorder (compilation of submitted articles)

Already our articles are generating record numbers of downloads and early citations. Clearly CNS Spectrums is "on the move."

Credit for our progress goes in large part to our editorial board, our reviewers and our field editors. All three of these groups have expanded notably in the past year, with kudos for lots of hard work and behindthe-scenes editing work especially by our incredible field editors, Carlos Zarate, Thomas Schlaepfer, Joseph Goldberg, deputy editor Tom Schwartz and newly appointed translational neuroscience field editor, Frank Tarazi. They are the workhorses of CNS Spectrums and deserve special thanks. In addition, they received the invaluable services of many reviewers during 2015, and these names are listed below.

Finally, we acknowledge the significant support of our publisher, Cambridge University Press and our with great credit due to, Lisa Arrington, managing editor and the heartbeat of CNS Spectrums, as well as her boss, Ann Avouris, our Senior Editor and the brains and visionary of CNS Spectrums. I look forward to the exciting developments that are already rolling out for our journal in 2016 and beyond and invite you all to submit your important work to our journal. 
CNS Spectrums 2015 peer reviewers (continued)

Paolo Cavedini

Anish V. Cherian

Carlo Cifani

Leslie Citrome

Emil Coccaro

Samuel Cortese

Caroline Davis

Jose de Leon

David DeMatteo

Sarah Desmarais

Joel Dvoskin

Mauro Giovanni Carta

Kristina Deligiannidis

Koen Demyttenaere

Maria Conceição do Rosário

Adrienne Einarson

Angela Favaro

Seena Fazel

Sherecce Fields

Erika Forbes

Ilana Frydman

Stephanie Fulton

Ashley Gearhardt

James Gilligan

Jon Grant

Mitzie Grant

William Greenberg

Gregory Hajcak

Nancy Hills

Eric Hollander

Rebecca Houston

Paul Jenkins

Alice Jones

Roger Jou

Siegfried Kasper

Andrew Kaufman

Sidney Kennedy

Deborah Kim

Kerri Kim

Pilyoung Kim

Marcel Kinsbourne

Daryl Kroner

Matthew Large

Kelly Lee
Royce Lee

Edythe London

Shari Lusskin

Rachel Marsh

José Menchón

Jonathan Meyer

Susan McElroy

Philip Harvey

C. Montano

Constance Moore

Laurel Morris

Jason Moser

Douglass Mossman

Astrid Mueller

Christoph Nissen

Dorte Nordholm

Michael Norko

Danielle Novick

Lauren Osborne

Stefano Pallanti

Jayendra Patel

Michael Poyurovsky

Phil Resnick

Brandon Reynolds

Benjamin Rose

Michael Rösler

Frank Schneier

Uri Shalev

Jaekyu Shin

Steven Simring

Manpreet Singh

J.M. Spikman

Ronnie Swift

Chad Sylvester

Michael Thase

Selim Tumkaya

Kees van Heeringen

Anna Van Meter

Lorenzetti Valentina

Richard Weisler

Robert Weisman

Stuart White

Glen Xiong 